\title{
Aggressive Behavior of a Whooping Crane
}

By F. W. LAHRMAN, Saskatchewan Museum of Natural History, Regina

Our knowledge of the behavior of the Whooping Crane (Grus americana) is so limited that practically any observation is a real contribution. The following description of aggressive behavior of a wild Crane toward a human being is probably unique.

In line with a continuing museum program of attempting to record photographically the occurrence of Whooping Cranes in Saskatchewan (see Blue Jay, 14: 39-42, 76-78, 81. 111-112) I travelled with Mr. Richard W. Fyfe on October 30, 1956 to investigate a report of three Whooping Cranes near Osage, Saskatchewan.

Three birds, a pair with one young, according to the local farmers, had been in this area for approximately two weeks. During this time they kept within an area of about four or five square miles and frequently fed on one particular wheat-stubble field.

When Fyfe and I arrived at this field by car at 12:30 p.m. the Cranes were present but they were far from any cover from which an observer might gain a vantage point. Though we were watching them from a parked car at more than 500 yards distance, the birds soon became uneasy and walked rapidly away from us. They finally flew to another field about one mile away.
I decided to lie in wait for them in a thick stand of weeds at the edge of the same stubble field on the chance that if they should return they might be within the range of the telephoto lens.

At about 1:30 p.m. the Cranes returned, alighting about 300 yards away from me. They at once began feeding in the usual manner with the youngster nearly always between the parents, each of which took turns feeding and standing on the alert. Occasionally all three would have their heads down for brief periods, and taking advantage of this I was able to rise slowly above the weeds to get a clear picture of them. But the watchful Cranes soon saw me and instantly tensed and stood on the alert. I thought they were about to fly. Then the bird which judged by the greater size to be the male deliberately began walkin rapidly towards me, followed by the other two, his neck craning this wa: and that as though curious to se what I might do. He continued thi behaviour until they had covere half the distance between us. The the male suddenly held his nec stiffly erect with the bill pointe downwards at a sharp angle (se photo), a posture which I had neve before seen in a Whooping Crane $i$ many hours of observation. Th peculiar "strained" posture was hel while the bird was fully erect an

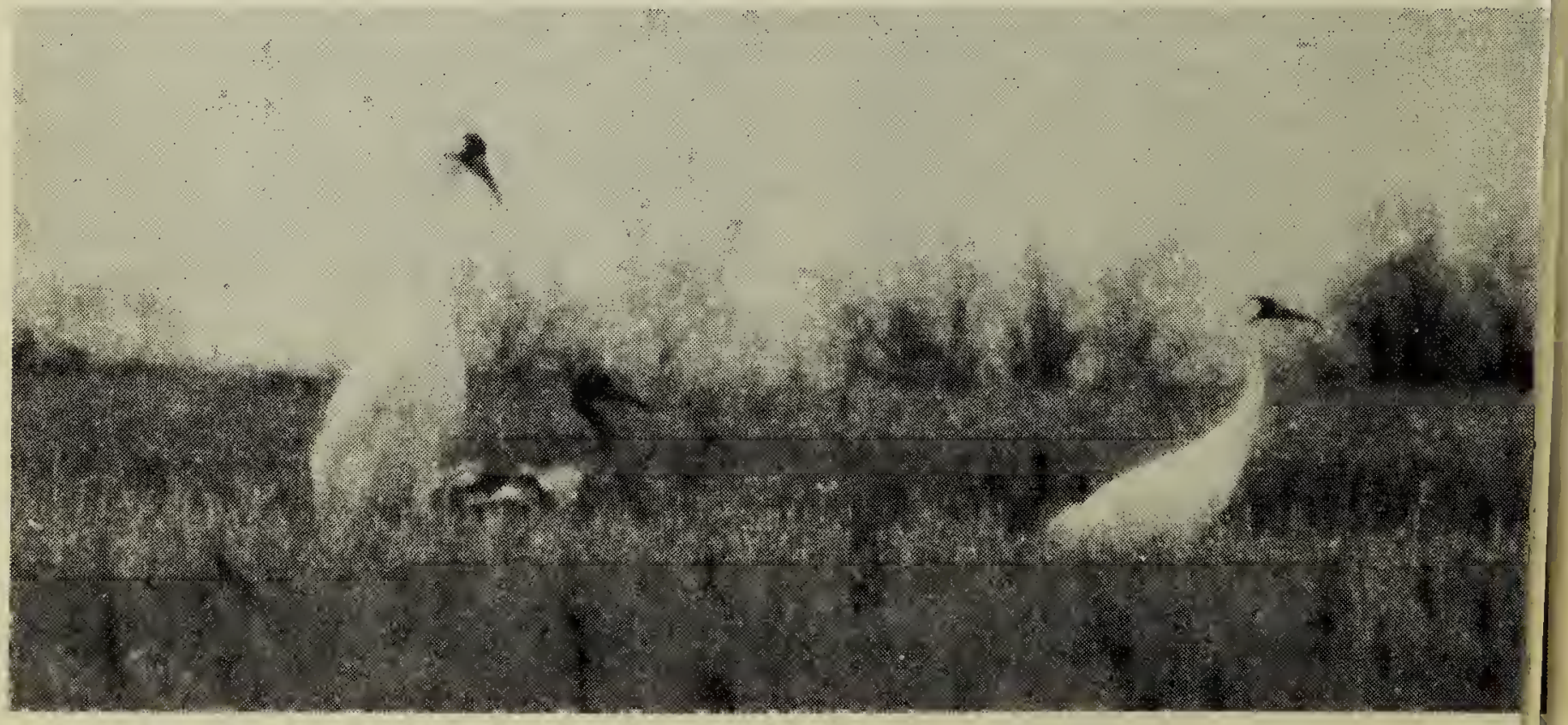

Photo by F. W. Lahrt

Cranes at 100 yards, just beginning to walk off to one side. Male, on left, with neck crooki 
walking. This was not all - much to my astonishment the male then suddenly thrust out his neck and actually pecked at the ground. He then brought his neck back to a normal position and resumed the typical head bobbing of a walking Crane. The bird's attitude while crooking his neck and pecking the ground appeared decidedly aggressive. As the male, still followed by the family, walked 50 yards closer to me he crooked his neck and pecked the ground more than a dozen times. (Exact figures were not obtained owing to the difficulty of alternately observing the Cranes and operating two cameras.) When he had approached to within about 100 yards from me he began walking slowly and suddenly ga ve several very loud and high-pitched calls, starting out like the rattling call of the Sandhill Crane (Grus canadensis) and rising in pitch to the end. He was answered im- mediately in kind by his mate which stood with the young about 15 yards away. During the next five minutes they called several times and twice I heard a faint whistled trill given by the young. In between calls the male continued to crook his neck and peck at the ground. Finally, though continuing to call, they turned abruptly. and walked quite leisurely away from me at a right angle for about 50 yards and then took wing and flew silently away to another field about a mile away.

I left the scene feeling extremely fortunate. Not only had I witnessed a remarkable performance and heard their rare calls but this had also been my first opportunity to photograph a family of Whooping Cranes with a young of the year. These are the first photos ever taken of young of the year during migration. Actually, these pictures were obtained only because the Cranes approached me as described.

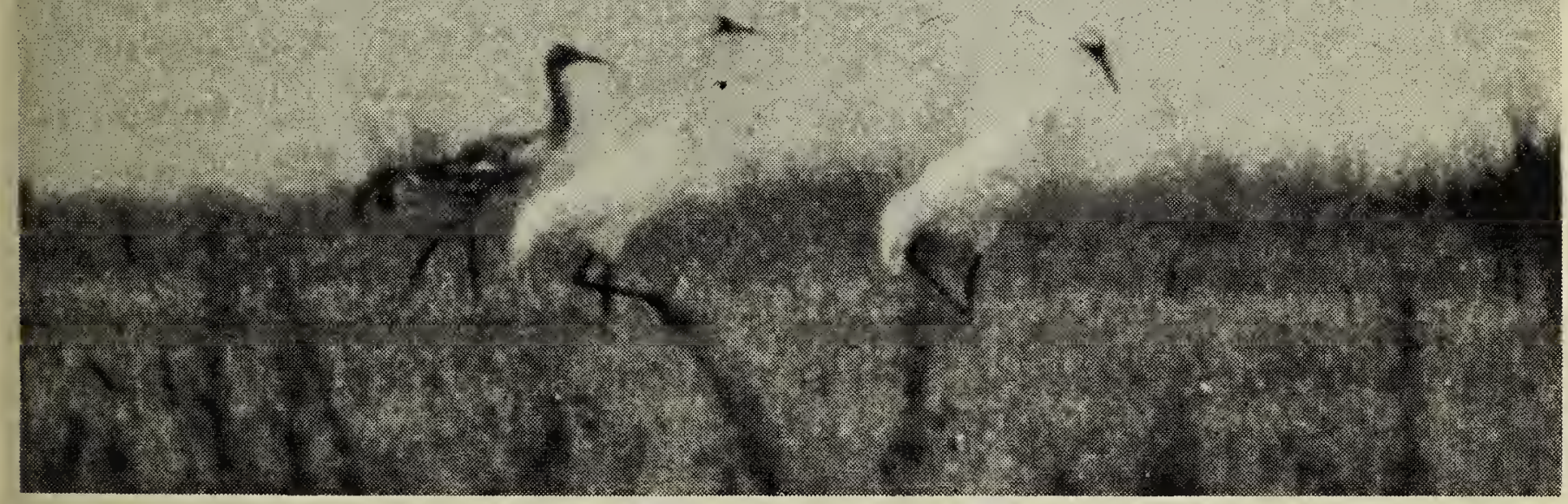

Photo by F. W. Lahrman Male in lead with neck crooked and about to peck ground.

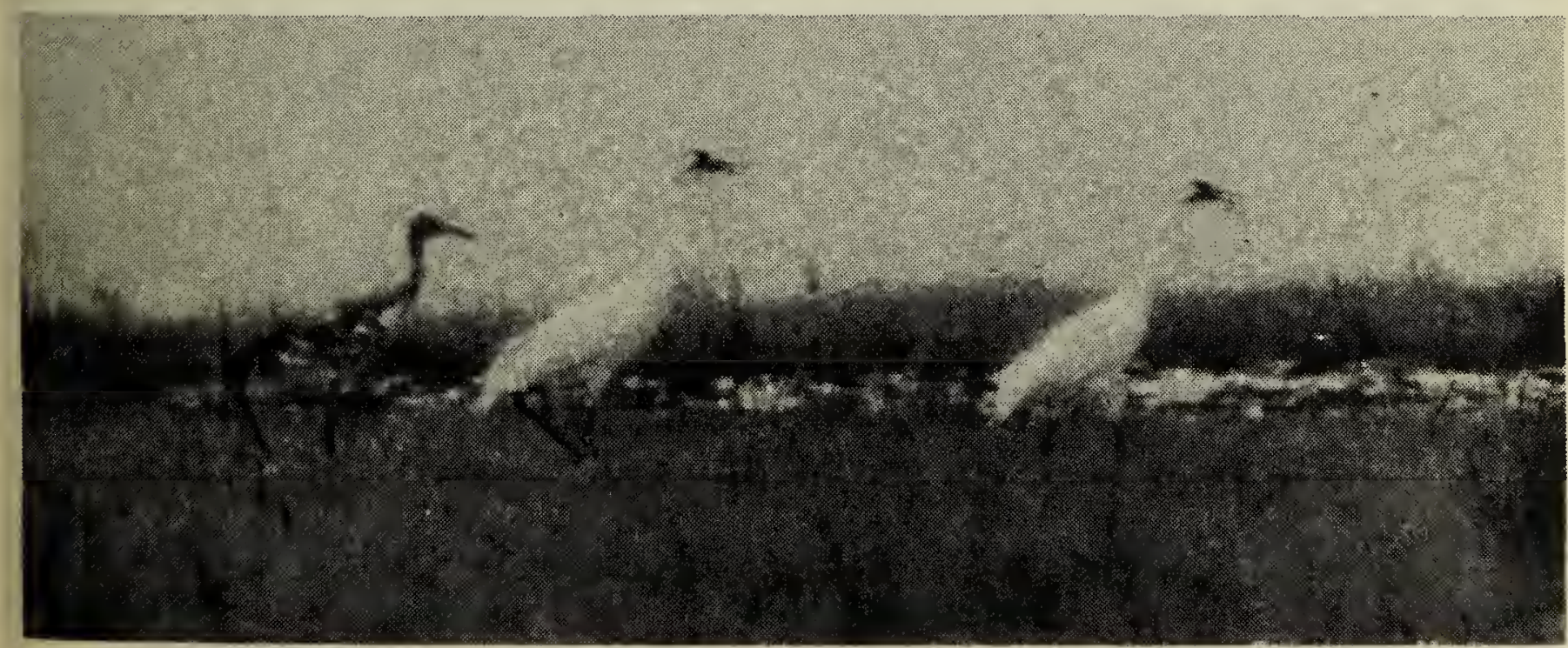

Both adult Cranes calling while leisurely walking away.

Photo by F. W. Lahrman 